\title{
The population genetics of Duchenne: natural and artificial selection in Duchenne muscular dystrophy
}

\author{
J H EDWARDS \\ From the Genetics Laboratory, Department of Biochemistry, University of Oxford, Oxford OX1 $3 Q U$.
}

SUmmary The dynamics of $\mathrm{X}$ linkage was derived by Haldane in $1935 .{ }^{1}$ It is clear that the majority of mutations to an X linked lethal are new and that methods of control based on relatives of known cases can have limited impact on future incidence. The ability to define and track neighbouring loci allows some carriers who are daughters of carriers to be detected, and possible carriers to be excluded, with high reliability. Fetal diagnosis may also be made in the same way, but not without a substantial casualty rate. The precision of such diagnosis by proxy is limited both by the estimate of the recombination fraction and its variance, and can rarely exceed $1 / \mathrm{s}$ where the recombinational data are based on $s$ informative meioses. Bracketing loci provide greater security from failure to diagnose cases but may involve substantial casualty rates. The estimation of both failure rates and casualty rates is discussed.

In spite of numerous recent articles on the application of new diagnostic methods in Duchenne muscular dystrophy, there appears to be no recent review of the natural dynamics of this disease or of the numerical consequences of artificial selection.

Since reproduction of affected subjects is extremely rare and heterozygotes are only rarely seriously weakened, the disease can be treated as an $\mathrm{X}$ linked lethal. This greatly simplifies the analysis. In general I will follow the terminology of Haldane $^{12}$ and disclaim any originality.

First it is necessary to define both the terms and the symbols used. The Greek symbols of Haldane have been widely miscopied and occasionally inverted. Theta and psi, the recombination fraction and its complement, the non-recombination or cosegregation fraction, can also be romanised with advantage.

The following will be used:

$g$ Proportion of mutations originating from maternal grandfather's locus.

$h$ Proportion of heterozygotes.

$k$ Ratio of mutation rates $(\mathrm{v} / \mathrm{u})$.

$q$ Gene frequency in newborn males.

$p$ Psi. The complement of theta.

$r$ Recurrence risk in boys after an affected boy.

$t$ Theta. The recombination fraction.

$u$ Haldane's ' $\mu$ '. Mutation rate at oogenesis.

$v$ Haldane's ' $v$ '. Mutation rate at spermatogenesis.

Received for publication 24 July 1986.

Accepted for publication 8 August 1986 $w$ The embryonic mutation rate. Defined as the proportion of mutations following a mutational event shortly after fertilisation.

I will use the terms defined below. Some of these words, such as simplex and multiplex, can be avoided by using simpler terms.

Bracketing loci. Pairs of loci astride the Duchenne locus.

Carrier. In this context a common and harmless abbreviation for heterozygote.

Carrier detection. Defining carrier status. This is only possible in the daughters of known carriers.

Carrier exclusion. Defining that a woman cannot be, or is very unlikely to be, a carrier.

Carrier prediction. The prediction of carrier status.

Embryonic mutation. A mutation occurring so early in embryonic life that a substantial proportion of germinal precursors are affected.

Familial case. A case arising in a family with another affected male.

Flanking loci. Variously used as a synonym of bracketing, and for loci very close to a gene, but not necessarily astride it.

Multiplex case. A synonym for familial case. 
New mutation. An ambiguous term variously used to relate to a sporadic case with or without evidence of maternal heterozygosity.

Obligate heterozygote. A woman who has transmitted two affected gametes, or has transmitted at least one and is related through female relatives to at least one other affected male.

Possible heterozygote. A woman who is at risk of being a heterozygote.

Probable heterozygote. A woman with a probability exceeding $50 \%$ of being a heterozygote.

Simplex family. Variously used, usually as a synonym for a sporadic case.

Sporadic case. The first known case in a family.

\section{Mutation and prevalence}

We assume a steady state population, with equal numbers of boys and girls at birth, in which a proportion of boys $q$ are, or will be, affected and a proportion $h$ of girls, and later mothers, are heterozygotes or carriers.

At .conception a proportion $u$ of ova have a new mutation on their $\mathrm{X}$ chromosome, as do a proportion $v$ of $\mathrm{X}$ bearing sperm. Haldane referred to these proportions, which are mutation rates, as mu and nu $(\mu, v)$, the Greek $\mathrm{m}$ and $\mathrm{n}$. It is convenient to write $u$ and $v$ which look similar and are also alphabetical neighbours. Later we will use $w$, the proportion of zygotes with a mutation acquired shortly after fertilisation. In addition to these new mutations, as half the ova of carriers convey the defect, and a proportion $h$ of women are carriers, $\mathrm{h} / 2$ ova will be affected from a mutation in a previous generation.

We clearly have the following equalities.

\section{Boys}

Girls

(1) $\mathrm{q}=\mathrm{h} / 2+\mathrm{u}$

(3) From

(2) $\mathrm{h}=\mathrm{h} / 2+\mathrm{u}+\mathrm{v}$

(4) From

(2) $\mathrm{h}=2 \mathrm{u}+2 \mathrm{v}$

and since either $u$ or $v$ could be zero the incidence of carriers in girls must be at least equal to the incidence of the disease in boys, but not more than twice this incidence. If, as seems consistent with most data, these mutation rates are similar, then, if they are assumed equal:
(5)
(6)
so that if
$\mathrm{u}=\mathrm{v}=\mathrm{q} / 3$
$\mathrm{h}=4 \mathrm{q} / 3$
$\mathrm{q}=1 / 3000$
(7)
$\mathrm{u}=\mathrm{v}=1 / 9000$ and $\mathrm{h}=1 / 2250$.

The proportion of boys with non-carrier mothers is (8)

(9) $\mathrm{u} /(\mathrm{h} / 2+\mathrm{u})$

or $u /(2 u+v)$.

When the relative mutation rates from the male and female is $k$, so that $\mathrm{k}=\mathrm{v} / \mathrm{u}$, this proportion is: (10) $1 /(2+k)$

which must lie between 0 and $1 / 2$, and is $1 / 3$ when $\mathrm{u}=\mathrm{v}$, or $\mathrm{k}=1$.

The proportion of mothers of carriers who are carriers is always $1 / 2$, whatever the relative mutation rate, and is equal to the proportion of daughters of carriers who are carriers. The mutation has a half life of one generation. These simple relationships can be displayed graphically (figs 1, 2, and 3).

Assuming equal mutation rates the incidence in various relatives is as shown in fig 4 .

The evidence for the equality of $u$ and $v$ is weak, although they are not demonstrably different on the limited data available. A priori, oogenesis and spermatogenesis are so different that they would not be expected to be equal.

The simplest estimate of the proportion of mothers who are carriers is derived from the

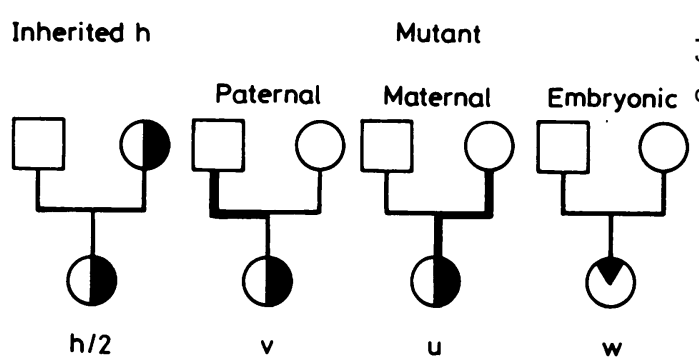

FIG 1 Distribution of mutational events leading to heterozygous women.

h
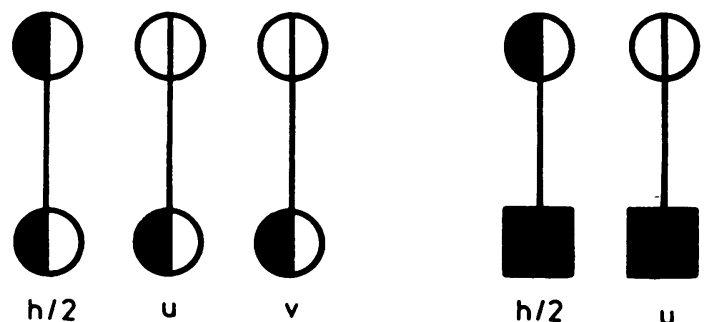

$\mathrm{h} / 2$

$\mathbf{u}$

$h=h / 2+u+v$

$q=h / 2+u$

FIG 2 Distribution of mutational events in successive generations. 

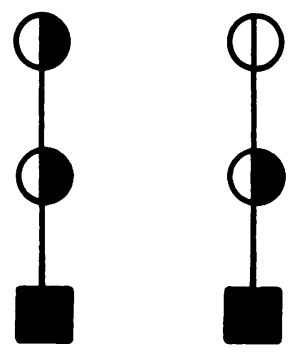

1

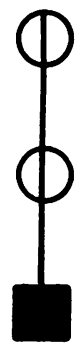

1
FIG 3 Three possible types of family by carrier status. If the mutation rates from male and female are equal, these are equally common.

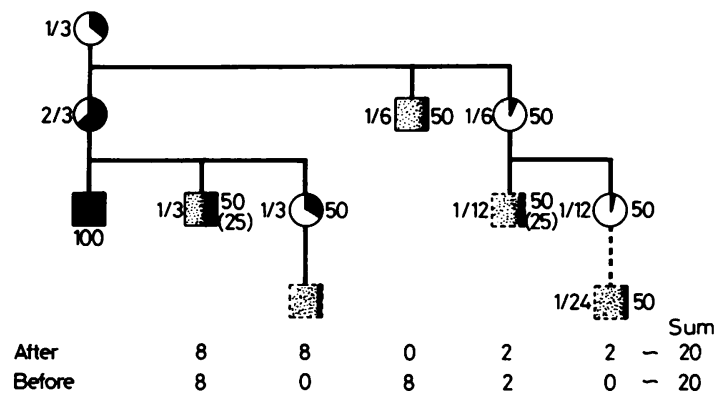

FIG 4 Recurrent Duchenne. Distribution of relatives and their risk in a stable two child population. The numbers may be read as percentages or as approximate annual numbers in the UK. After and before refer to the percentages with an affected relative.

recurrence risk $r$; this is $1 / 2$ for carriers and effectively zero for non-carriers, so that

$$
\begin{aligned}
r & =(1 / 2)(u+v) /(2 u+v) \\
2 r & =(1+k) /(2+k) \\
k & =(4 r-1) /(1-2 r) .
\end{aligned}
$$

Most data sufficiently old to be unbiased by any strong correlation between carrier status and reproduction suggest a value of $r$ of about $1 / 4$, implying all mutations are maternal. That is, half the mothers of new cases would be carriers. However, various tests on the mothers consistently show carrier rates of well over $1 / 2$, usually consistent with at least $2 / 3$ being carriers. ${ }^{34}$

Efficient estimation of $r$, on a sibship by sibship basis, is now simple on small computers ${ }^{5}$; although consistent with equal rates it is suggestive of a higher rate from the male if embryonic mutation is ignored.

Even efficient estimates from such data provide very limited information. Direct information, using DNA markers, is now accumulating on the parental

origin. If $\mathrm{k}=1$, a fifth of mutations will originate from the maternal grandfather, and if all mutations are from the male, a half will be from the maternal grandfather.

If this proportion is defined as $g$, then

$$
\mathrm{g}=\mathrm{v} /(\mathrm{v}+\mathrm{h} / 2+\mathrm{u}+\mathrm{u})
$$

where $v, \mathrm{~h} / 2+\mathrm{u}$, and $u$ are contributions from grandfather, grandmother, and mother.

This reduces to

$$
\begin{aligned}
& \mathrm{g}=1 /(2+3 / \mathrm{k}) \\
& \mathrm{k}=3 \mathrm{~g} /(1-2 \mathrm{~g})
\end{aligned}
$$

The simplest explanation of this discrepancy between the segregational and the phenotypic data is that a proportion of mutational events occurs before the germ line and muscle cell precursors have separated, so that only a minority of the ova shed by carriers whose mothers are not carriers convey the mutation: that is, they are germinal mosaics. It is convenient to call this event embryonic mutation. In view of the complexity of events shortly after fertilisation, and the development of $\mathrm{X}$ inactivation, the first few cell divisions are a likely time for accidents, including aberrant segmental inactivation which is a plausible explanation for this disorder. As the two $\mathrm{X}$ chromosomes cannot be assumed to be equally prone to such errors at this stage, any attempt to estimate $w$ is difficult due to confounding with $u$ and $v$.

If almost all mutations occurred at this time, and if the paternal and maternal $\mathrm{X}$ chromosomes were equally liable to this mutation, where $h$ refers exclusively to carriers who inherit a mutant $X$ from their mother, the stability relationship would be:

If almost all mutations happen in this way then the number of affected ova which are in germinal mosaics must equal the number in non-mosaic carriers, and mosaic carriers must greatly exceed other carriers.

After a sporadic case it would not be possible to predict normality on the basis of the bracketing loci resembling those of a normal brother. It would, however, be safe to infer normality from nonidentity with the affected brother.

It would be possible to recognise mosaic carriers provided they have normal and affected sons with identical bracketing loci at which there is maternal heterozygosity. Linkage studies, conducted by counting recombinants and non-recombinants, should distinguish these potential founder carriers from other carriers, as their sons could show spurious recombination or apparent conversion within bracketing loci. 


\section{Prospects of reducing the incidence at birth}

\section{SCREENING PROCEDURES}

Fig 5 shows what would happen if various subjects were exposed to accurate and complete screening in a population whose members responded to any positive test by termination. The scale may be read as a percentage, or as approximately equal to raw numbers in Great Britain, which, with a population of about 50 million, has about 100 births and deaths a year with Duchenne muscular dystrophy.

The prospect of making any substantial reduction in the numbers born is distressingly low. Cases due to deficiencies, ${ }^{6}$ which might be the majority if a battery of probes within the critical segment were available, or if pulsed field electrophoresis were feasible for routine use, might allow DNA from male fetuses available from other routine procedures to be screened. As it is clear that the lesion is not consistent, and that most first cases in a family will differ from most other cases in the same population, any lesion except a deficiency may be resistant to any screening technique possible at present. However, a slight reduction in a common disease confers as much benefit as a major reduction in a rare disease, and screening male fetuses when amniocentesis or chorion biopsy is indicated for other purposes would be advantageous if reliable.

The question "what proportion of cases in a community has a common origin?" is frequently posed. A formal answer requires a knowledge of population structure, but approximations based on the mathematically simple population, in which

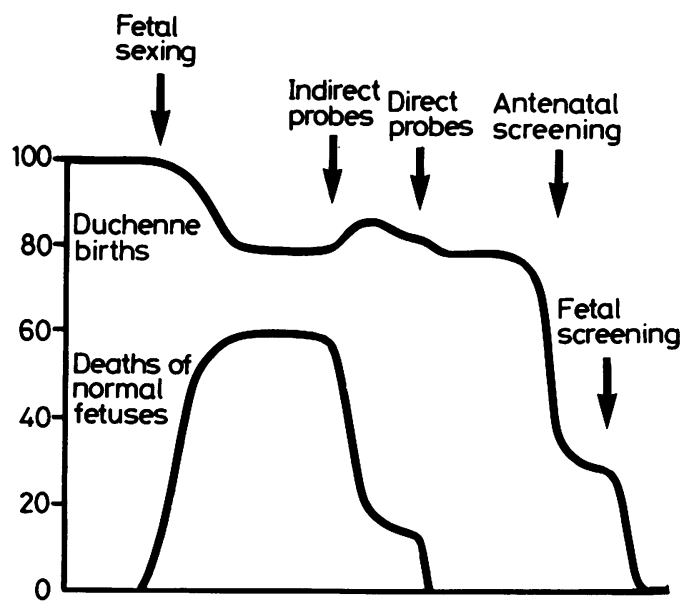

FIG 5 Consequences of complete ascertainment and fetal diagnosis with termination. Percentages or approximate anuwal numbers in the UK. Antenatal screening refers to mother's phenotype. Mutation rates assumed equal. every woman has two children with an equal expectation of boys and girls, may give results close to a more realistic model, or may, after elaborate algebra involving multiple integrals, lead to very similar predictions due to parameters which are not obviously irrelevant largely cancelling out. ${ }^{7}$

The half life of the mutant is one generation, since only half the daughters will inherit it and none of the sons will transmit it. Similarly, only half the mothers of carriers will be carriers. The chance in an all-female pedigree of any woman being a carrier can be defined if the connection between any two women is described by writing $\mathrm{M}$ for mother and $\mathrm{D}$ for daughter. A sister is then MD, a first cousin MMDD, and so on. The chance of a mother of a carrier being a carrier is $1 / 2$. The chance of a child being both a daughter and a carrier is $1 / 4$, so that the risk is

$$
1 /\left(2^{\mathrm{M}} \times 4^{\mathrm{D}}\right) \text {. }
$$

The possible numbers of sisters, first cousins, second cousins, when $M$ and $D$, etc, in such a breeding structure is shown in table 1 and fig 6 . No allowance is made for the substantial mitigating influence of normal brothers.

The proportion of carriers in sisters and cousins of

TABLE 1 Maximum number of contemporary female relatives, of the same generation, connected through women and their carrier risk, ignoring the reduced risk due to unaffected males. Based on two child population.

\begin{tabular}{llclll}
\hline Relative & Links & Max No & Risks & Risk & Product \\
\hline Sister & MD & 1 & $2 / 3 \times 1 / 2$ & $1 / 3$ & $1 / 3$ \\
1st cousin & MMDD & 4 & $1 / 3 \times 1 / 16$ & $1 / 48$ & $1 / 12$ \\
2nd cousin & MMMDDD & 8 & $1 / 6 \times 1 / 64$ & $1 / 384$ & $1 / 48$ \\
3rd cousin & MMMMDDDD & 16 & $1 / 12 \times 1 / 256$ & $1 / 3072$ & $1 / 192$ \\
\hline
\end{tabular}

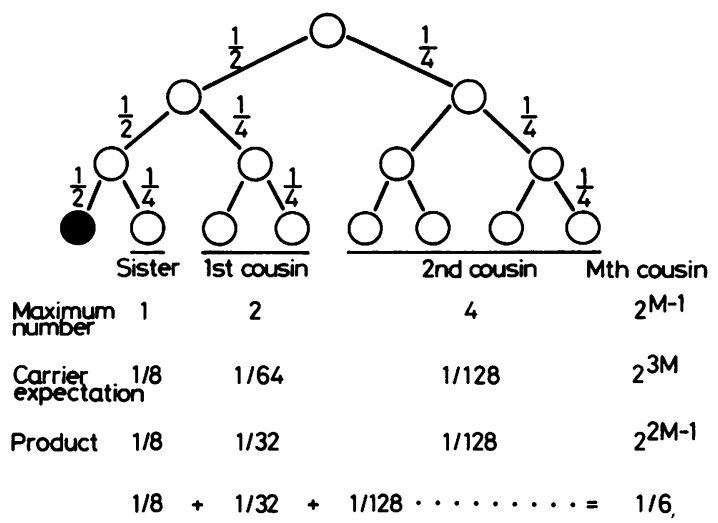

FIG 6 Distribution of maximum carrier risk to relatives of carrier. 
a known carrier, and when the cousins are of degree $\mathrm{N}$ (sisters are cousins of zero degree) is:

(21) $2^{(\mathrm{N}-1)} /\left(2^{\mathrm{N}} \times 4^{\mathrm{N}}\right)$

and the sum of all these terms is $1 / 6$, allowing for the effects of normal brothers.

By third cousins the risk of inheriting this mutant is less than that of acquiring a new mutation. That is, even if related as third cousins, any two mothers with affected boys and no other affected relatives are more likely than not to have boys with different mutations.

It is clear that, even in a small community, most apparently sporadic cases will be new mutants, and the number of independent mutations will be well over half the number of boys.

If, as is implied by the similar artificial breeding structure drawn in fig $5,20 \%$ of boys have a previous relative and $20 \%$ will have a subsequent relative, then about two-thirds of boys $(80 \%$ of $80 \%$ or $64 \%$ ) will neither have had, nor have, another case in their families. This accords with both clinical experience and the formulation above. The prospect of preventing or avoiding this majority is very limited.

It is clear that, whether or not embryonic mutation is common, most carriers in the population will have no affected relative and carrier girls are commoner than Duchenne boys. As manifesting carriers are rarely diagnosed in the absence of an affected male relative it must be assumed that the majority are not diagnosed and may make up a substantial proportion of girls and women with unclassified, and usually mild, muscular dystrophy.

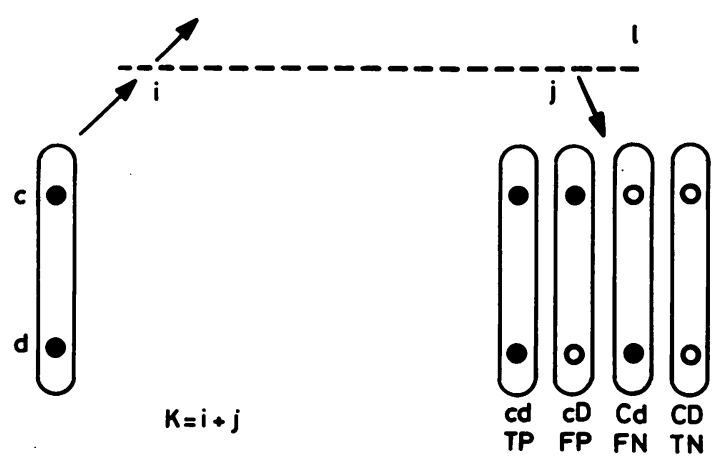

FIG 7 Diagram showing use of an allele at locus $C$ to predict an allele at locus $D$. A chromosome with the same allele at locus $C$ may differ at locus $D$ due to mutation at locus $D$ or recombination. Where the allele at locus $C$ differs, locus $D$ may not differ due to recombination. The chromosomes are related through $k$ meioses (i backward and $j$ forward) and identity by descent may or may not be demonstrable. TP, FP, FN, and TN relate to true positive, false positive, false negative, and true negative.

\section{Segregation with linked loci}

It is now possible to detect nearby alleles with codominant expression using probes, allowing predictions to be made based on co-segregation. This introduces difficult problems even when the recombination fractions and relative mutation rates are exactly known, and insoluble problems when they are merely estimated. However, as with squaring the circle, there are adequate approximate solutions.

Basically, if there are previous data that a locus has co-segregated $n$ times out of $s$, the expectation of this happening again is about

(22) $(\mathrm{n}+1) /(\mathrm{s}+2)$ rather than n/s.

This result, due to Laplace, ${ }^{8}$ is intuitively reasonable, since a recombination fraction of $0 \cdot 1$ based on one recombinant out of 10 is obviously less secure than one based on 10 out of 100 , although both give the same value of $\mathrm{n} / \mathrm{s}$, which is the maximum likelihood solution. Maximum likelihood estimates are inappropriate in this context, since the potential mother's problem is 'what is the mean risk' and not 'what is the most likely risk'. A similar problem arises with radioactive decay. The most likely moment for the next disintegration is always 'now'. However this maximum likelihood solution is of little practical value and it is more useful to estimate the mean life rather than the most likely life.

Where linkage values are inferred indirectly from Morton's $z$ scores, we can use a similar approximation to derive the 'predictive recombination fraction' which will always exceed the real recombination fraction. For a maximum lod score of ' $z$ ' the error rate per meiosis will always be at least $1 / 5 z$, and may be almost $1 / 3 z$. In order to estimate this we must convert the lod scores into equivalent observations, that is, the number of recombinants and meioses which would give the maximum value of $z$ at the same recombination value, and derive the predictive recombination value from this. ${ }^{9} 10$

If the maximum value $z$ occurs at a recombination value $t$, then the equivalent number of meioses $s$ is (24) $\quad \mathrm{z} /(\operatorname{tog}(2 \mathrm{t})+\operatorname{plog}(2 \mathrm{p}))$ where $\mathrm{p}=1-\mathrm{t}$ which is approximately

(25) $33 \cdot 3(\mathrm{t}+0 \cdot 1)$ (table 2).

The equivalent number of recombinants is ts.

The predictive value, that is the expectation of the next observation being a recombinant, is then about (27)

or very roughly $(\mathrm{ts}+1) /(\mathrm{s}+2)$

$$
t+1 / s \text { or } t+1 / 3 z
$$


TABLE 2 Equivalent meioses per unit value of $z$ and an approximation.

\begin{tabular}{|c|c|c|}
\hline$T$ & $E q$ & $\begin{array}{l}(t+0 \cdot 1) \\
\times 33 \cdot 3\end{array}$ \\
\hline 0.00 & $3 \cdot 32$ & $3 \cdot 33$ \\
\hline 0.02 & 3.87 & 4.00 \\
\hline 0.04 & $4 \cdot 38$ & $4 \cdot 67$ \\
\hline 0.06 & 4.94 & $5 \cdot 33$ \\
\hline 0.08 & $5 \cdot 56$ & 6.00 \\
\hline $0 \cdot 10$ & $6 \cdot 26$ & 6.67 \\
\hline 0.12 & 7.06 & $7 \cdot 34$ \\
\hline $0 \cdot 14$ & 7.99 & 8.00 \\
\hline 0.16 & 9.09 & 8.67 \\
\hline 0.18 & $10 \cdot 39$ & $9 \cdot 34$ \\
\hline
\end{tabular}

In practice the minimal error rate is usually between $\mathrm{m} / 3 \mathrm{z}$ and $\mathrm{m} / 5 \mathrm{z}$ where $m$ is the number of meioses connecting the known with the unknown phenotype.

Table 3 shows the 'predictive' value for various values of the recombination fraction $(t)$ and the maximum lod at which it occurs, using the approximation of Laplace ${ }^{8}$ which is exact for an a priori rectangular distribution of possible values of theta from 0 to $1 \cdot 0$. The fact that this distribution is limited to 0 to 0.5 makes little difference if the linkage is tight.

Fortunately these limitations are rapidly ceasing to be realistic problems now that there are bracketing variants in Duchenne. Provided that there are no crossovers between these, and they are fairly close, the chance of error due to a double recombination cannot be more than

$(\mathrm{t} / 2)^{2}$

where $t$ is the predictive recombination fraction between the bracketing loci. Although not obvious, the worst case is that in which the disease locus is exactly midway between the bracketing loci. The possibility of one crossover between bracketing loci, leading to a 'grey area' of uncertainty, has to be considered in any assessment of risk of a procedure. Where this is ignored, very high precision has been claimed. The chance of a crossover leading, in practice, to termination is as discussed above; the $\frac{\mathbb{D}}{\stackrel{(}{(}}$ chance of the fetus being affected is dependent on $\stackrel{+}{-}$ the position of the disease locus. In practice the act $\underset{\vec{D}}{\vec{D}}$ of recombination usually inhibits nearby recombination, and even more reliable predictions may be expected.

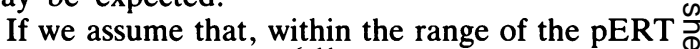
and junction fragments ${ }^{611}$ and the outlying probes $\stackrel{\mathbb{Q}}{\square}$ C7 and 754, we can assume reliability if all travel as a block, and unreliability if they do not, the linkage $\vec{\circ}$ problem can be resolved by simple methods. While there is usually little point in defining the exact $\vec{\omega}$ degree of risk further, the problem remains one of general mathematical interest. It can be solved exactly if the recombination fraction is known by i using Ott's programme. ${ }^{12}{ }^{13}$ However, the recombination fraction cannot be known, and this is only of reliable if the data are very extensive and the linkage $\underset{-}{-}$ not very close, so that at least 10 recombinants have 을 been observed. That is, the prediction is correct only if predictive power is poor. More complicated procedures, involving integrating hypervolumes on various reasonable a priori assumptions, ${ }^{14}$ are avail- $\frac{\Phi}{3}$ able. The use of Ott's programme, ${ }^{12}$ entering the 'predictive' recombination fraction for the nearest neighbour, should give a close approximation. $\mathscr{\odot}$ Where bracketing loci are available no computation. should be necessary.

The serious problem, which is not resolved by an⿴囗十 number of probes, however close, is the inability to define whether the Duchenne locus is normal or mutant unless the potential carrier's mother is $\frac{\mathbb{Q}}{\alpha}$ known to be a carrier. This is a most serious $\Rightarrow$ limitation, since this limits control with low casualty rates to a proportion of potential carriers in that $\bar{\sigma}$ minority of families with more than one affected member. The casualty rate of normal fetuses must increase rapidly as the circle of anxiety, or of intervention, extends from the mother of the known:case to other female relatives.

If we consider the sporadic case without further evidence (fig 3), then terminating sons with the $₹$

TABLE 3 Approximate estimates of the expectation that the next meiotic event will show recombination for various values of the recombination rate at which likelihood is maximised.

\begin{tabular}{|c|c|c|c|c|c|c|c|c|c|c|}
\hline$t / z \max$ & 1.00 & 2.00 & 3.00 & 4.00 & 5.00 & 6.00 & 7.00 & 8.00 & 9.00 & $10 \cdot 00$ \\
\hline 0.00 & $0 \cdot 19$ & $0 \cdot 12$ & 0.08 & 0.07 & 0.05 & 0.05 & 0.04 & 0.03 & 0.03 & 0.03 \\
\hline 0.01 & $0 \cdot 18$ & $0 \cdot 12$ & 0.09 & 0.07 & 0.06 & 0.05 & 0.05 & 0.04 & 0.04 & 0.04 \\
\hline 0.02 & $0 \cdot 18$ & $0 \cdot 12$ & 0.09 & 0.07 & 0.06 & 0.06 & 0.05 & 0.05 & 0.05 & 0.04 \\
\hline 0.03 & $0 \cdot 18$ & $0 \cdot 12$ & $0 \cdot 10$ & 0.08 & 0.07 & 0.07 & 0.06 & 0.06 & 0.05 & 0.05 \\
\hline 0.04 & $0 \cdot 18$ & $0 \cdot 13$ & $0 \cdot 10$ & 0.09 & 0.08 & 0.07 & 0.07 & 0.06 & 0.06 & 0.06 \\
\hline 0.05 & $0 \cdot 19$ & 0.13 & $0 \cdot 11$ & 0.09 & 0.09 & 0.08 & 0.08 & 0.07 & 0.07 & 0.07 \\
\hline 0.06 & $0 \cdot 19$ & 0.13 & $0 \cdot 11$ & $0 \cdot 10$ & 0.09 & 0.09 & 0.08 & 0.08 & 0.08 & 0.08 \\
\hline 0.07 & 0.19 & $0 \cdot 14$ & $0 \cdot 12$ & $0 \cdot 11$ & $0 \cdot 10$ & $0 \cdot 10$ & 0.09 & 0.09 & 0.09 & 0.09 \\
\hline 0.08 & 0.19 & $0 \cdot 14$ & $0 \cdot 12$ & $0 \cdot 11$ & 0.11 & $0 \cdot 10$ & $0 \cdot 10$ & $0 \cdot 10$ & $0 \cdot 10$ & 0.09 \\
\hline 0.09 & 0.19 & $0 \cdot 15$ & $0 \cdot 13$ & 0.12 & $0 \cdot 12$ & $0 \cdot 11$ & $0 \cdot 11$ & $0 \cdot 11$ & $0 \cdot 10$ & $0 \cdot 10$ \\
\hline $0 \cdot 10$ & $0 \cdot 20$ & $0 \cdot 16$ & $0 \cdot 14$ & $0 \cdot 13$ & $0 \cdot 12$ & $0 \cdot 12$ & $0 \cdot 12$ & $0 \cdot 12$ & 0.11 & $0 \cdot 11$ \\
\hline
\end{tabular}


same Duchenne segment as the affected boy will always lead to death of a normal fetus if the mother is not a carrier: that is, a third of those terminated will be unaffected and, as only half will be terminated, this will lead, on average, to the termination of three fetuses, one unaffected and two affected, out of six male fetuses tested. Even this is a great advance on the two-thirds casualty rate from terminating boys of mothers with an affected boy and no other affected relatives.

In the case of a maternal aunt of an affected boy, the risk is only $1 / 3$ even if the same chromosomal segment is present, and any termination will usually be of a normal fetus. While great help can be received from information on healthy brothers and from tests of creatine kinase, as clearly demonstrated recently, ${ }^{15}$ in practice any substantial reduction in incidence can only be achieved with a substantial casualty rate. However, great benefits in reducing anxiety are now possible through 'carrier exclusion' or defined absence of the offending chromosome in a female relative. About two-thirds of sisters and five-sixths of their daughters will not have the offending chromosomal segment, and the proportion of women in whom carrier exclusion can be demonstrated will increase with increasing numbers of probes. Rare alleles are particularly valuable as they may be used to infer across gaps in a pedigree.

The proportions of the four possible outcomes, true positive, false positive, false negative, and true negative (fig 7), are easily computed. In practice these two types of error have very different implications.

The error, failure, and casualty rates are given in table 4 . In words, the failure rate is the proportion of those tested who are affected, but were thought not to be, and the casualty rate is the proportion of those who were not affected, but thought to be. The sum of these gives the total error rate. The acceptability of any procedure based on termination must depend on the size of these two errors and the severity of the condition, and will differ from condition to condition, and from person to person. Fig 5 and table 4 show the failure and casualty rates for various relatives ignoring the substantial information available from creatine kinase. It is clear that the casualty rate rapidly becomes excessive, and this is mainly due to mutation rather than recombination, even with loosely linked probes.

\section{The estimation of carrier status using information from normal males}

The risk of a woman being a carrier, connected in any pedigree to the closest known carrier through female relatives, is easily calculated if the mitigating effects of the normal male are ignored. This risk fades into insignificance, in practical terms, by the third counsinship.

Where allowance is to be made for normal males, or for likelihood ratios based on creatine kinase or related tests, the probability is most easily computed by working in odds ratios. These are directly related to probabilities, but lead to simpler arithmetic: they are also more easily comprehended by most relatives of patients, since the language of betting is more widely understood than that of probabilities. If the odds ratio is expressed as $a: b$ the probability is $\mathrm{a} /(\mathrm{a}+\mathrm{b})$.

The mother whose only son is affected, and who knows nothing of her family history, has, assuming equal mutation rates from male and female, a probability of $2 / 3$ of being a carrier and $1 / 3$ of not being a carrier.

Her odds ratio for being a carrier is:

$$
2 / 3: 1 / 3
$$

or $2: 1$.

As half the carriers have a carrier mother, the three categories of (1) grandmother and mother carriers, (2) mother only a carrier, and (3) neither a carrier are necessarily equal, with an odds ratio of 2:1 1:1:1 (fig 3).

TABLE 4 Distribution of errors for various carrier risks, recombination fractions $(t)$, and numbers of meiotic events ( $m$ ). The headings TP, FP, FN, TN relate to true positive, false positive, false negative, and true negative.

\begin{tabular}{|c|c|c|c|c|c|c|c|c|c|}
\hline $\begin{array}{l}\text { Carrier } \\
\text { risk }\end{array}$ & $t$ & $m$ & $T P$ & $F P$ & $F N$ & $T N$ & $\begin{array}{l}\text { Failure } \\
\text { rate }\end{array}$ & $\begin{array}{l}\text { Casualty } \\
\text { rate }\end{array}$ & $\begin{array}{l}\text { Error } \\
\text { rate }\end{array}$ \\
\hline 1 & 0 & & 1 & 0 & 0 & 1 & 0 & 0 & 0 \\
\hline $2 / 3$ & 0 & & 2 & 1 & 0 & 3 & 0 & $1 / 6$ & $1 / 6$ \\
\hline $1 / 2$ & 0 & & 1 & 1 & 0 & 2 & 0 & $1 / 4$ & $1 / 4$ \\
\hline $1 / 3$ & 0 & & 1 & 2 & 0 & 3 & 0 & $1 / 3$ & $1 / 3$ \\
\hline $1 / 4$ & 0 & & 1 & 3 & 0 & 4 & 0 & $3 / 8$ & $3 / 8$ \\
\hline 1 & $0 \cdot 1$ & 1 & 9 & 1 & 1 & 9 & $1 / 20$ & $1 / 20$ & $1 / 10$ \\
\hline 1 & $0 \cdot 1$ & 2 & 8 & 2 & 2 & 8 & $2 / 20$ & $2 / 20$ & $1 / 5$ \\
\hline $1 / 2$ & $0 \cdot 1$ & 2 & 4 & 6 & 2 & 8 & $2 / 20$ & $6 / 20$ & $2 / 5$ \\
\hline
\end{tabular}


The ease of expressing more than two situations in this way greatly simplifies the analysis. It is usual to define odds ratios in terms of bad to good, or, in this case, carrier to non-carrier.

Such families usually include unaffected males, and every unaffected male halves the odds ratio of his mother being a carrier. This is because a woman who also has one normal son obviously has a lower risk, since if she were a carrier she might have had both her sons affected. A carrier would have a half chance of the second son being unaffected, while a non-carrier would necessarily have an unaffected son, or have a change of unity of an unaffected son. If the odds ratio were initially $1: 1$ then after a normal son the odds ratio would be $1 / 2: 1$, which is the same as $1: 2$. We merely 'multiply downwards' the previous odds ratio by $1: 2$, or, if we are considering the three situations above, by the odds ratios.

$$
1: 1: 2 .
$$

Writing this in tabular form:

Odds ratio in the absence

of any pedigree information $2: 1$

Odds ratio from one normal

son

Product

$$
\frac{1 / 2: 1}{1: 1}
$$

and this is the same as $1: 1$ or one out of two possibilities, or a probability of $1 / 2$, or $50 \%$.

In the full representation the odds ratios become

\section{Product \\ Percentages $25 \quad 25 \quad 50$}

$$
\begin{aligned}
& 1: 1: 1 \\
& 1: 1: 2 \\
& \hline 1: 1:
\end{aligned}
$$

We can accumulate any number of odds ratios, provided they are independent. For example, if we had some biochemical result with a level found in a proportion $p n$ of non-carriers and $p c$ of carriers, we could include the odds ratio of pc:pn and multiply this by the other odds ratios.

This analysis can be made far more complicated by dealing with probabilities rather than odds ratios, and by using words implying time, such as prior and posterior, implicitly limiting the analysis to two sets of information in a defined order. This approach is sometimes called Bayesian, but while it may use his symbolism it does not use Bayes's theorem of the equiprobability of similar events based on a knowledge of identity of mechanism and an ignorance of initial state. ${ }^{16}$ This approach has been presented very lucidly by Emery. ${ }^{17}$

Logically, we are enumerating possibilities which are defined, rather than making assumptions of complete ignorance. Our ignorance of the relative mutation rates is not complete. Male and female gametes are known to be very different and, in any case, their differences can feature explicitly in the
TABLE 5 Spread sheet of likelihoods for pedigrees

\begin{tabular}{|c|c|c|c|c|}
\hline $\begin{array}{l}\text { Mode } \\
\text { of } \\
\text { inheritance }\end{array}$ & $\begin{array}{l}\mathrm{C} \\
\mathrm{C} \\
* \\
\end{array}$ & $\begin{array}{l}\mathrm{N} \\
\mathrm{C} \\
* \\
\end{array}$ & $\begin{array}{l}\mathrm{N} \\
\mathrm{N} \\
*\end{array}$ & \multirow[t]{6}{*}{$\begin{array}{l}\text { G mother } \\
\text { Mother } \\
\text { Son }\end{array}$} \\
\hline $\begin{array}{l}\text { Gmaternal odds g } \\
\text { No uncles }\end{array}$ & $\begin{array}{l}\mathrm{g} \\
\mathrm{V} / 2^{\mathrm{u}}\end{array}$ & \multicolumn{2}{|c|}{$\begin{array}{l}1 \\
1 \\
\end{array}$} & \\
\hline $\begin{array}{ll}\text { Maternal odds } & \text { m } \\
\text { No brothers } & \text { b }\end{array}$ & \multicolumn{2}{|c|}{$\begin{array}{l}\mathrm{m} \\
\mathrm{V} / 2^{\mathrm{b}}\end{array}$} & $\begin{array}{l}1 \\
1\end{array}$ & \\
\hline Mutation ratio $\quad k$ & \multicolumn{2}{|c|}{1} & $1 / \mathbf{k}$ & \\
\hline $\begin{array}{l}\text { Multiply down } \\
\text { Likelihoods } \\
\text { Percentages }\end{array}$ & $\begin{array}{l}\text { lcc } \\
\text { pcc }\end{array}$ & $\begin{array}{l}\text { Inc } \\
\text { pnc }\end{array}$ & \multirow[t]{2}{*}{$\begin{array}{l}\text { lnn } \\
\text { pnn }\end{array}$} & \\
\hline Maternal carrier & \multicolumn{2}{|c|}{ pcc + pnc } & & \\
\hline
\end{tabular}
summarised by numbers of maternal uncles and brothers of an affected boy. Percentages are derived from likelihoods, for example, $p c c=100 \times \mathrm{lcc} / \mathrm{sum}$.

$\mathrm{N}=$ normal, $\mathrm{C}=$ carrier, $^{*}=$ affected son

TABLE 6 Spread sheet of likelihoods for pedigrees summarised by numbers of maternal uncles and brothers of an affected boy and for odds ratios, $g$ and $m$, of grandmother and maternal carrier status, assuming equal

\begin{tabular}{|c|c|c|c|c|}
\hline $\begin{array}{l}\text { Mode } \\
\text { of } \\
\text { inheritance }\end{array}$ & $\begin{array}{l}\mathrm{C} \\
\mathrm{C} \\
*\end{array}$ & $\begin{array}{l}\mathrm{N} \\
\mathrm{C} \\
*\end{array}$ & $\begin{array}{l}\mathrm{N} \\
\mathrm{N} \\
*\end{array}$ & \multirow{6}{*}{$\begin{array}{l}\text { G mothe을 } \\
\text { Mother } \\
\text { Son }\end{array}$} \\
\hline $\begin{array}{l}\text { G maternal odds } \\
\text { No uncles }\end{array}$ & $\begin{array}{l}\mathbf{g} \\
1\end{array}$ & \multicolumn{2}{|c|}{$\begin{array}{l}1 \\
2^{u}\end{array}$} & \\
\hline $\begin{array}{l}\text { Maternal odds } \\
\text { No brothers }\end{array}$ & \multicolumn{2}{|c|}{$\begin{array}{l}m \\
1\end{array}$} & $2^{b}$ & \\
\hline Mutation ratio & \multicolumn{2}{|c|}{$k$} & 1 & \\
\hline $\begin{array}{l}\text { Multiply down } \\
\text { Likelihoods } \\
\text { Percentages }\end{array}$ & $\begin{array}{l}\text { lcc } \\
\text { pcc }\end{array}$ & $\begin{array}{l}\text { Inc } \\
\text { pnc }\end{array}$ & \multirow[t]{2}{*}{$\begin{array}{l}\ln n \\
\text { pnn }\end{array}$} & \\
\hline Maternal carrier & \multicolumn{2}{|c|}{$\mathrm{pcc}+\mathrm{pnc}$} & & \\
\hline
\end{tabular}
mutation rates. Percentages are derived from likelihoods, for example, $p c c=100 \times \mathrm{lcc} / \mathrm{sum}$. Modified to replace fractions by multiplying columns consistently.

$\mathrm{N}=$ normal, $\mathrm{C}=$ carrier $^{*}=$ affected son

TABLE 7 Example of above for boy with two maternal

\begin{tabular}{|c|c|c|c|c|c|}
\hline $\begin{array}{l}\text { Mode } \\
\text { of } \\
\text { inheritance }\end{array}$ & & $\begin{array}{l}\mathrm{C} \\
\mathrm{C} \\
*\end{array}$ & $\begin{array}{l}\mathrm{N} \\
\mathrm{C} \\
*\end{array}$ & $\begin{array}{l}\mathrm{N} \\
\mathrm{N} \\
*\end{array}$ & \multirow[t]{5}{*}{$\begin{array}{l}\text { G mother } \\
\text { Mother } \\
\text { Son }\end{array}$} \\
\hline $\begin{array}{l}\text { G maternal odds } \\
\text { No uncles }\end{array}$ & $\begin{array}{l}1 \\
2\end{array}$ & $\begin{array}{l}1 \\
1\end{array}$ & \multicolumn{2}{|c|}{$\begin{array}{l}1 \\
8 \\
\end{array}$} & \\
\hline $\begin{array}{l}\text { Maternal odds } \\
\text { No brothers }\end{array}$ & $\begin{array}{l}3 \\
1\end{array}$ & \multicolumn{2}{|c|}{$\begin{array}{l}3 \\
1\end{array}$} & $\begin{array}{l}1 \\
2\end{array}$ & \\
\hline $\begin{array}{l}\text { Multiply down } \\
\text { Likelihoods } \\
\text { Percentages }\end{array}$ & & $\begin{array}{l}3 \\
7 \\
\end{array}$ & $\begin{array}{l}24 \\
56 \\
\end{array}$ & $\begin{array}{l}16 \\
37\end{array}$ & \\
\hline Maternal carrier & & \multicolumn{2}{|c|}{63} & & \\
\hline
\end{tabular}
uncles and one brother, all unaffected, whose mother has an odds ratio of 3:1 favouring carrier status. Relative mutation rates omitted.

$\mathrm{N}=$ normal, $\mathrm{C}=$ carrier, ${ }^{*}=$ affected son 
equations. Even if they are not demonstrably different, there are data from which these relative rates can be estimated. The notation of the probability method is Bayesian, but Bayes's formulation is not the same as Bayes's theorem.

Logically, the problem relates to 'unfinished games of chance' where odds have to be laid due to a

TABLE 8 Computation of odds for various categories. $G$ and $M$ refer to non-carrier grandmothers and mothers respectively. This layout has the advantage that multiplication is from left to right and addition vertical. Any number of rows and columns can be accommodated. For example, the last line could be split to give the categories $G \mathrm{~g} \mathrm{~m}^{*}$ and $\mathrm{g} \mathrm{g} \mathrm{m}^{*}$, each with initial odds of a half, where the first $G$ or $g$ refers to the mother's mother's mother.

\begin{tabular}{llllllll}
\hline Type & Odds & Brothers & M.CK & Uncles & GM.CK & Product & $\%$ \\
\hline & & 2 & 132 & 1 & - & & \\
$\mathrm{G} \mathrm{M}^{*}$ & 1 & 1 & 1 & 1 & 1 & $1 \cdot 0$ & 18 \\
$\mathrm{G} \mathrm{m}^{*}$ & 1 & $1 / 4$ & $6 \cdot 4$ & 1 & 1 & $3 \cdot 1$ & 54 \\
$\mathrm{~g} \mathrm{~m}^{*}$ & 1 & $1 / 4$ & 6.4 & $1 / 2$ & 1 & $1 \cdot 6$ & 28 \\
& & & & & & $5 \cdot 7$ & 100 \\
\hline
\end{tabular}

TABLE 9 Computation of likelihoods for probes with recombination fractions $0 \cdot 1$ and $0 \cdot 01$. These can be multiplied by those derived from data on sons and phenotypes. As they stand they are appropriate for a woman heterozygous for probe $C$ with alleles $C$ and $c . D$ is the Duchenne locus with alleles $D$ and $d$, the lower case being the mutant allele. The factor 1/2 for all sons is omitted as it cancels out later.

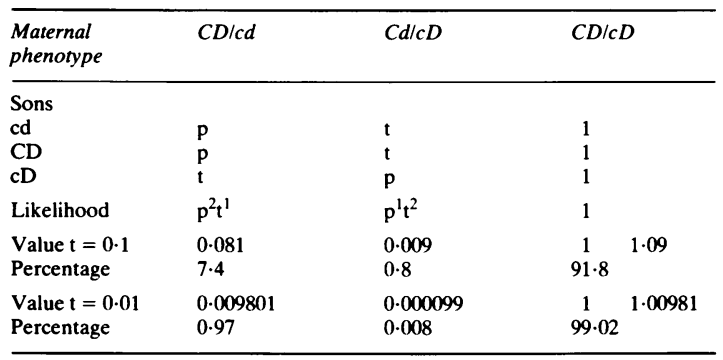

game being interrupted. For a clear and detailed discussion see a letter from Pascal to Fermat in $1654,{ }^{18}$ written over a century before Bayes's posthumous publication.

In most cases presenting clinically, it is only necessary to consider three exhaustive and exclusive possibilities (fig 3). In the first, the mutation is found in the affected boy, but not in his mother. In the second, it is conveyed through his mother, but not derived from her mother. In the third, it is conveyed through both his mother and her mother. These can be displayed in the form of a simple spread-sheet, and this is shown in tables 5 and 6 , and with a worked example (table 7).

Information from probes is easily accommodated, although the circumstances are so variable that it is difficult to advance a generalised approach. The estimated recombination fraction must be modified to the predictive form, as discussed above. In practice, probe data are easy to interpret from annotated pedigrees when there has been no crossover: when a crossover has occurred even approximate predictions may be difficult (exact ones are impossible). In practice, with a disorder as severe as Duchenne, there is little consumer tolerance of uncertainty and its exact computation is of limited clinical value. Table 8 shows example of enumeration and computation of all contingencies. While the principles are simple, this approach can involve numerous columns in a large family sparsely provided with obligate carriers. Even if the computations are correct, substantial casualty rates will be inevitable in most situations. Worked examples are shown in tables 9 and 10.

An elegant computer programme ${ }^{19}$ provides a simple solution, which has been extensively tested on real data. ${ }^{15}$ No extensive test of the various programmes has yet been made on simulated data. In practise, this is a field in which molecular biology is advancing faster than methods of statistical analysis, which will become irrelevant as soon as

TABLE 10 Computation of likelihoods for similar case involving bracketing loci $C$ and E and the Duchenne locus D. Recombination between $C D$ and $D E$ assumed to be $0 \cdot 1$. The factor $1 / 4$ for each son omitted (these cancel out). On these data the probability of the mother being a carrier is about $15 \%$. For clarity, such terms as $p_{1} t_{2}$ are written pt, the order defining the subscript.

\begin{tabular}{|c|c|c|c|c|c|c|}
\hline $\begin{array}{l}\text { Maternal } \\
\text { phenotype }\end{array}$ & $C D E / c d e$ & $C D e / c d E$ & $C d E / c D e$ & $C d e / c D E$ & $C D E / c D e$ & $C D e / c D E$ \\
\hline $\begin{array}{l}\text { Sons } \\
\text { cde } \\
\text { CDE } \\
\text { CDe }\end{array}$ & $\begin{array}{l}\mathrm{pp} \\
\mathrm{pp} \\
\mathrm{pt}\end{array}$ & $\begin{array}{l}\mathrm{pt} \\
\mathrm{pt} \\
\mathrm{pp}\end{array}$ & $\begin{array}{l}\mathrm{tt} \\
\mathrm{tt} \\
\mathrm{tp}\end{array}$ & $\begin{array}{l}\mathrm{tp} \\
\mathrm{tp} \\
\mathrm{tt}\end{array}$ & $\begin{array}{l}p p+t t \\
p p+t t \\
p t+t p\end{array}$ & $\begin{array}{l}\mathrm{pt}+\mathrm{tp} \\
\mathrm{pt}+\mathrm{tp} \\
\mathrm{pp}+\mathrm{tt}\end{array}$ \\
\hline $\begin{array}{l}\text { Likelihood } \\
t 1=0 \cdot 1\end{array}$ & $p^{3} p^{2} t^{0} t^{1}$ & $p^{3} p^{1} t^{0} t^{2}$ & $p^{0} p^{1} t^{3} t^{2}$ & $p^{0} p^{2} p^{3} t^{1}$ & & \\
\hline $\mathrm{t} 2=0.1$ & 0.05905 & 0.00656 & $0 \cdot 000009$ & 0.00081 & $0 \cdot 1211$ & 0.2660 \\
\hline Percentages & $13 \cdot 02$ & 1.45 & 0.002 & $0 \cdot 18$ & $26 \cdot 67$ & $58 \cdot 65$ \\
\hline
\end{tabular}


direct diagnostic procedures are developed and perfected.

\section{References}

' Haldane JBS. The rate of spontaneous mutation of a human gene. J Genet 1935;31:317-26.

2 Haldane JBS. Mutation in the sex-linked recessive type of muscular dystrophy. A possible sex difference. Ann Hum Genet 1956;20:344-7.

3 Thompson MW, Percy ME, Hutton EM, Williams WR. Mutation in the muscular dystrophies. In: Hook EB, Porter IH, eds. Population and biological aspects of human mutation. New York: Academic Press, 1981.

+ Lane RJM, Robinow M, Roses AD. The genetic status of mothers of isolated cases of Duchenne muscular dystrophy. $J$ Med Genet 1983;20:1-11.

5 Edwards JH. Duchenne muscular dystrophy. J Med Genet 1984;21:77.

${ }^{6}$ Kunkel LM, Hejtmancik JF, Caskey CT, et al. Analysis of deletions in DNA from patients with Becker and Duchenne muscular dystrophy. Nature 1986;322:73-7.

7 Thompson EA. The history of a lethal X-linked mutant. IMA Journal of Mathematics Applied in Medicine and Biology 1985;2:75-92.

${ }^{8}$ Laplace S. Essai philosophique sur les probabilites, 1795.

${ }^{9}$ Edwards JH. The analysis of X-linkage. Ann Hum Genet 1971;34:229-35.

${ }^{10}$ Edwards JH. Old problems in new clothes. Lancet 1985;11:40.

1 Worton RG. X;autosome translocation in females with Duchenne or Becker muscular dystrophy. Nature 1986;322:292.

$12 \mathrm{Ott} \mathrm{J}$. Estimation of the recombination fraction in human pedigrees: efficient computation of the likelihood for human linkage studies. Am J Hum Genet 1974;26:588-97.

13 Conneally P, Wallace MR, Gusella JF, Wexler NS. Huntington's disease. Estimation of genetic status using linked genetic markers. Genet Epidemiol 1984;1:81-8.

14 Clayton JF. A computer programme to calculate risk in X linked disorders using multiple marker loci. J Med Genet 1986;23:35-9.

15 Williams H, Sarfarazi M, Brown C, Thomas N, Harper PS. The use of flanking markers in prediction for Duchenne muscular dystrophy. Arch Dis Child 1986;61:218-22.

${ }^{16}$ Bayes T. An essay towards solving a problem in the doctrine of chances. Philos Trans $R$ Soc Lond 1763;53:370-418. Reprinted in Studies in the history of probability and statistics. IX. Thomas Bayes's essay towards solving a problem in the doctrine of chances (with a biographical note by GA Barnard). Biometrika 1958;45:293-315.

17 Emery AEH. Methodology in medical genetics. Edinburgh: Churchill Livingstone, 1986.

18 Pascal B, 1654. For text see Jacquard A. Les probabilites. Paris: Presses Universitaires de France, 1974. See also Pascal's collected work (letter of 29 July 1654).

19 Sarfarazi M, Williams H. A computer programme for estimation of genetic risk in $\mathrm{X}$ linked disorders combining pedigree and DNA probe data with other conditional information. $J$ Med Genet 1986;23:40-5.

Correspondence and requests for reprints to Professor J H Edwards, Genetics Laboratory, Department of Biochemistry, University of Oxford, South Parks Road, Oxford OX1 3QU. 